\title{
A mixed psychiatric and somatic care unit for trauma patients: 10 years of experience in an urban level I trauma center in the Netherlands
}

\author{
Lisette Dekker ${ }^{1}$ (D) Hansje M. Heller ${ }^{2}$. Jessica E. van der Meij ${ }^{1}$ Annelies E. J. Toor ${ }^{3} \cdot$ Leo M. G. Geeraedts $^{1,2,3}$
}

Received: 15 November 2018 / Accepted: 6 February 2019 / Published online: 15 February 2019

(c) Springer-Verlag GmbH Germany, part of Springer Nature 2019

\begin{abstract}
Background A medical-psychiatric unit (MPU) is a special ward where staff is trained in caring for patients with psychiatric or behavioural problems that need hospitalisation for physical health problems. It is well known that these patients are at higher risk of complications and have a longer length of stay resulting in higher costs than patients without psychiatric comorbidity. The objective of this study was to analyse the trauma patient population of the first 10 years of existence of the MPU in a level I trauma center.

Patients and methods A retrospective analysis was performed in 2-year cohorts from 2006 to 2016. All trauma patients admitted to the MPU were compared with the overall trauma patient population in VUmc. Data (psychiatric diagnosis, substance abuse, trauma scores, surgical interventions, complications, mortality) were extracted from individual patient notes and the Regional Trauma Registry.

Results 258 patients were identified. $36 \%$ of all patients had a history of previous psychiatric admission and $30 \%$ had attempted suicide at least once in their lifetime. Substance abuse was the most common psychiatric diagnosis (39\%), with psychotic disorder (28\%) in second place. The median hospital stay was 21 days. Median MPU length of stay was 10 days (range 1-160). Injuries were self-inflicted in 57\%. The most common mechanism of injury was fall from height with intentional jumping in second place. Penetrating injury rate was $24 \%$ and $33 \%$ had an ISS $\geq 16$, compared to $5 \%$ and $15 \%$, respectively, in the overall trauma patient population. The most common injuries were those of the head and neck. Complication rate was $49 \%$.

Conclusion Trauma patients that were admitted to the MPU of an urban level I trauma center had serious psychiatric comorbidity as well as high injury severity. Penetrating injury was much more common than in the overall trauma patient population. A high complication rate was noted. The high psychiatric comorbidity and the complicated care warrants combined psychiatric and somatic (nursing) care for this subpopulation of trauma patients. This should be taken into account in the prehospital triage to a trauma center. The institution of a MPU in level I trauma centers is recommended.
\end{abstract}

Keywords Trauma $\cdot$ Injury $\cdot$ Self-inflicted $\cdot$ Psychiatric $\cdot$ Medical-psychiatric unit

\section{Introduction}

Lisette Dekker

lisettedekker06@hotmail.com

1 Department of Surgery, Section Trauma Surgery, Amsterdam University Medical Center, Location VUmc, P.O. Box 7057, 1007 MB Amsterdam, The Netherlands

2 Department of Hospital Psychiatry, Amsterdam University Medical Center, Location VUmc, Amsterdam, The Netherlands

3 Trauma Network North-West, Amsterdam University Medical Center, Location VUmc, Amsterdam, The Netherlands
Patients that need trauma care as well as psychiatric treatment simultaneously are common. We are increasingly confronted with psychiatric patients with physical injuries. Since 2007, an increasing suicide rate is observed in the Netherlands [1]. Accordingly, although not as impressive, the number of suicide attempts has increased as well [2].

Recent literature shows that patients with a mental disorder have a higher risk of medical complications following physical injury than patients without a mental disorder $[3,4]$. Also this group usually shows more health problems and less patient compliance [3]. Consequently, patients 
with recognised psychiatric disorders admitted for trauma surgery have a longer length of stay resulting in higher costs than trauma patients without psychiatric disorders [5].

In location VUmc of Amsterdam University Medical Center, those patients are admitted to the medical-psychiatric unit (MPU), a semi-closed unit where the staff is trained in medical (and surgical) as well as psychiatric care. The trauma surgeon is the primary treating physician but the psychiatrist is closely involved in the multidisciplinary treatment programme for these patients.

The existence of a MPU is of importance because patients with physical as well as psychiatric disorders are repeatedly refused admission either to a medical/surgical or psychiatric ward. And when eventually admitted, they may be discharged or transferred too early to another ward because of behavioural issues. Often, the complexity of care for these patients may exceed the competence level of the usual healthcare worker [6]. A retrospective case-note study from our MPU [7] shows that most patients who were secondarily admitted to the MPU had behavioural problems (e.g. extreme demanding behaviour) at the ward of the treating specialty.

Limited literature is available on the topic of combined care at a MPU, while the number of this specific group of patients in need of this care is increasing [5, 6, 8, 9]. 9\% of all the patients referred to the MPU are trauma patients [7].

To maintain and improve high quality at the MPU, insight into the characteristics of this select patient group is necessary.

Our objective is to study and analyse the characteristics of trauma patients admitted to the MPU and search for possible trends that may trigger projects for further improvement of care.

\section{Patients and methods}

\section{Study design}

A retrospective study during a 10 -year period in a level I trauma center (VUmc) with a special medical-psychiatric unit (MPU) was performed. This MPU is characterised as a type IV unit [10], which primarily provides psychiatric care with a high level of medical acuity. The MPU has eight beds. When necessary the MPU can be closed and camera surveillance is possible. Data were extracted from individual patient notes, Chipsoft data files and the regional trauma registry (part of the Dutch National Trauma Registry). This retrospective study was approved by the local Medical Ethical Committee of VU University Medical Center.

\section{Patient population}

All adult trauma patients (18 years or older) admitted to the MPU between January 2006 and December 2015 with single or multiple injuries as a result of unintentional or selfinflicted trauma, and with a comorbid psychiatric disorder, were included. The search in the Research Data Platform of the VUmc revealed 258 records. Patients were categorised in groups by admission every 2 years.

\section{Study parameters}

The study parameters included: age at the time of admission, sex, psychiatric diagnosis (DSM-IV), history of attempted suicide, previous psychiatric consultation and admission, alcohol/drug abuse, trauma mechanism, intentional injury, type of transport, mechanism of injury, deployment of the Mobile Medical Team (MMT), Glasgow Coma Scale (GCS), Revised Trauma Score (RTS), injury patterns; Abbreviated Injury Scale (AIS) and the ISS [11], surgical interventions, complications, re-interventions, length of stay, ventilator days, re-admission, destination of discharge and mortality. GCS, RTS and ISS were dichotomized utilising clinically relevant cut-off points. Injury patterns by AIS codes were described for: "head and neck", "thorax", "abdomen" and "extremities". Each surgical intervention even at the same session was scored as separate interventions.

\section{Data analysis}

Descriptive analyses were performed on all data. Data are presented as median with the range, or as number with the percentage between brackets. AIS '08 codes were retrieved and mapped to AIS '98. SPSS software, version 22 was used.

\section{Results}

\section{Patient characteristics and length of stay}

Two hundred and fifty-eight patients were analysed. Some patients were admitted to the general ward initially and then transferred to the MPU. There was a remarkable waiting list whereby transfers to the MPU were not infrequently delayed. Table 1 shows patients characteristics. The male to female ratio was 1.8 . The median age was 46 (range 18-94). $36 \%$ of the patients had a history of admission on a psychiatric ward and $63 \%$ had consulted a health worker before because of their psychiatric symptoms. $30 \%$ had attempted suicide at least once before. Most patients had a primary psychiatric disorder, but a notable amount of $10 \%$ had a cognitive 
Table 1 Patient characteristics of trauma patients admitted at MPU

\begin{tabular}{|c|c|c|c|c|c|c|}
\hline & 2006-2007 & 2008-2009 & 2010-2011 & 2012-2013 & 2014-2015 & Total \\
\hline \multicolumn{7}{|l|}{ Gender, $N(\%)$} \\
\hline Men & $27(57.4)$ & $29(64.4)$ & $31(66.0)$ & $37(69.8)$ & $41(62.1)$ & $165(64.0)$ \\
\hline Women & $20(42.6)$ & $16(35.6)$ & $16(34.0)$ & $16(30.2)$ & $25(37.9)$ & $93(36.0)$ \\
\hline Age on admission, median (range) & $56(21-91)$ & $43(18-87)$ & $49(20-86)$ & $43(19-92)$ & $46(20-94)$ & $46(18-94)$ \\
\hline Previous suicide attempt(s), $N(\%)$ & $13(28.9)$ & $12(26.7)$ & $16(34.0)$ & $13(25.5)$ & $22(34,3)$ & $76(30.2)$ \\
\hline Previous psychiatric consultation & $19(43.2)$ & $33(73.3)$ & $29(61.7)$ & $35(67.3)$ & $43(67.2)$ & $159(63.1)$ \\
\hline Previous psychiatric admission & $8(18.6)$ & $17(37.8)$ & $20(42.6)$ & $24(47.1)$ & $20(33.3)$ & $89(36.2)$ \\
\hline \multicolumn{7}{|l|}{ No. of psychiatric disorders, $N(\%)$} \\
\hline 1 & $24(51.1)$ & $24(53.3)$ & $25(53.2)$ & $28(52.8)$ & $31(47.0)$ & $132(51.2)$ \\
\hline 2 & $10(21.3)$ & $13(28.9)$ & $13(27.7)$ & $13(24.5)$ & $20(30.3)$ & $69(26.7)$ \\
\hline 3 & $3(6.4)$ & $6(13.3)$ & $5(10.6)$ & $6(11.3)$ & $7(10.6)$ & $27(10.5)$ \\
\hline 4 & $1(2.1)$ & $1(2.2)$ & 0 & $1(1.9)$ & $1(1.5)$ & $4(1.6)$ \\
\hline 5 & 0 & 0 & 0 & 0 & $1(1.5)$ & $1(0.4)$ \\
\hline \multicolumn{7}{|l|}{ Psychiatric disorder, $N(\%)$} \\
\hline Psychotic disorder & $10(21.3)$ & $13(28.9)$ & $14(29.8)$ & $15(28.3)$ & $19(28.8)$ & $71(27.5)$ \\
\hline Mood disorder & $12(25.5)$ & $12(26.7)$ & $8(17.0)$ & $12(22.6)$ & $24(36.4)$ & $68(26.4)$ \\
\hline Substance abuse disorder & $17(36.2)$ & $22(48.9)$ & $21(44.7)$ & $16(30.2)$ & $25(37.9)$ & $101(39.1)$ \\
\hline Personality disorder & $4(8.5)$ & $12(26.7)$ & $7(14.9)$ & $15(28.3)$ & $16(24.2)$ & $54(20.9)$ \\
\hline Cognitive disorder & $7(14.9)$ & $2(4.5)$ & $6(12.8)$ & $8(15.1)$ & $2(3.0)$ & $25(9.7)$ \\
\hline Other & $7(14.9)$ & $10(22.2)$ & $9(19.1)$ & $10(18.9)$ & $15(22.7)$ & $51(19.7)$ \\
\hline \multicolumn{7}{|l|}{ Blood alcohol concentration (BAC) $\% o, N(\%)$} \\
\hline Mentioned & $8(17.0)$ & $4(8.9)$ & $3(6.4)$ & $2(3.8)$ & $2(3.0)$ & $19(7.4)$ \\
\hline BAC $0.51-1.80 \%$ & 0 & $2(4.4)$ & $3(6.4)$ & 0 & $5(7.6)$ & $10(3.9)$ \\
\hline $\mathrm{BAC}>1.81 \%$ & $3(6.4)$ & $6(13.3)$ & $9(19.1)$ & $4(7.5)$ & $6(9.1)$ & $28(10.9)$ \\
\hline \multicolumn{7}{|c|}{ (Presumed) street drugs use at admission, $N(\%)$} \\
\hline Cannabis (hasj or marihuana) & $2(4.3)$ & $2(4.4)$ & $3(6.4)$ & $5(9.4)$ & $6(9.1)$ & $18(7.0)$ \\
\hline Cocaine/crack & $1(2.1)$ & $7(15.6)$ & $2(4.3)$ & $2(3.8)$ & $3(4.5)$ & $15(5.8)$ \\
\hline Amphetamine (speed) & $1(2.1)$ & 0 & 0 & $1(1.9)$ & $2(3.0)$ & $4(1.6)$ \\
\hline MDMA (XTC) & 0 & $1(2.2)$ & $1(2.1)$ & 0 & $1(1.5)$ & $3(1.2)$ \\
\hline GHB & 0 & 0 & 0 & $2(3.8)$ & 0 & $2(0.8)$ \\
\hline LSD & 0 & 0 & 0 & $1(1.9)$ & 0 & $1(0.4)$ \\
\hline Heroin & $1(2.1)$ & $1(2.2)$ & 0 & 0 & 0 & $2(0.8)$ \\
\hline \multicolumn{7}{|l|}{ Intentional medication overdose } \\
\hline Opiates & $3(6.4)$ & 0 & $1(2.1)$ & $2(3.8)$ & $2(3.0)$ & $8(3.1)$ \\
\hline Benzodiazepines & $5(10.6)$ & $3(6.7)$ & 0 & $2(3.8)$ & $3(4.5)$ & $13(5.0)$ \\
\hline Antipsychotics & $1(2.1)$ & 0 & $1(2.1)$ & 0 & 0 & $2(0.8)$ \\
\hline Antidepressants & $1(2.1)$ & 0 & $1(2.1)$ & $1(1.9)$ & $2(3.0)$ & $5(1.9)$ \\
\hline Lithium & $1(2.1)$ & 0 & 0 & 0 & $1(1.5)$ & $2(0.8)$ \\
\hline Length of stay hospital (days), median (range) & $20.63(1-146)$ & $26.33(1-126)$ & $24.26(1-160)$ & $20.67(1-116)$ & $19.01(1-123)$ & $20.57(1-160)$ \\
\hline Length of stay MPU (days), median (range) & $8.04(1-43)$ & $9.94(1-74)$ & $13.01(1-160)$ & $10.02(1-80)$ & $10.10(0-103)$ & $10.02(0-160)$ \\
\hline $\mathrm{ICU}, N(\%)$ & $14(29.8)$ & $17(37.8)$ & $15(31.9)$ & $18(34.0)$ & $27(40.9)$ & $91(35.3)$ \\
\hline Length of stay ICU (days), median (range) & $0(0-33)$ & $0(0-48)$ & $0(0-16)$ & $0(0-18)$ & $0(0-32)$ & $3.6(0-48)$ \\
\hline MCU, N (\%) & $4(8.5)$ & $13(28.9)$ & $7(14.9)$ & $9(17.0)$ & $19(28.8)$ & $52(20.2)$ \\
\hline Length of stay MCU, mean (range) & $0(0-11)$ & $0(0-11)$ & $0(0-5)$ & $0(0-21)$ & $0(0-24)$ & $0(0-24)$ \\
\hline Ventilator days, mean (range) & $1.78(0-22)$ & $1.50(0-14)$ & $0.64(0-9)$ & $1.00(0-15)$ & $1.46(0-15)$ & $1.29(0-22)$ \\
\hline Total & $47(18.2)$ & $45(17.4)$ & $47(18.2)$ & $53(20.5)$ & $66(25.6)$ & $258(100)$ \\
\hline
\end{tabular}


disorder as dementia, mental retardation or cognitive impairment caused by a tumour. Twenty-four patients had acquired psychiatric disorders caused by traumatic brain injury. Six of them had no primary psychiatric disorder on admission but a post-concussion syndrome made quality of care at the general ward impossible. Eighteen other patients were admitted to the MPU because of a severe delirium or behavioural issues. One hundred and thirty-two (51\%) had one psychiatric disorder, 69 (27\%) had two, and 27 (11\%) had three.

The hospital stay ranged between 1 and 160 days with a median of 21 days. The MPU stay ranged between 1 and 160 days with a median of 10 days. No significant changes were found over time regarding the patient characteristics.

\section{Psychiatric diagnosis}

$39 \%$ had a substance use disorder (Table 1). The secondmost common psychiatric disorder was psychotic disorder (28\%). 26\% had mood disorders. $21 \%$ had personality disorders. Cognitive disorders consisted off severe postoperative delirium or post-concussion syndrome. The category "other" included anxiety disorders, PTSS, impulse-control disorders, autism spectrum disorders, dissociative disorder, ADHD, factitious disorder, somatoform disorder and adjustment disorder.

In $22 \%$ of all cases alcohol was involved. Twenty-eight patients had a blood alcohol concentration higher than $1.81 \%$. From 19 patients there was no blood alcohol concentration documented but it was described positive in the discharge letter. From 35 patients, it is presumed that they used drugs at time of admission and this was documented as detectable urine levels of intoxication substances as well as patients medical history. Six used two sorts of drugs, and two even used three. Cannabis was used most common. Twenty-four patients had taken an overdose of medication and six even had two sorts of medication. Most commonly used were benzodiazepines. Ten patients used both alcohol and drugs, four had both alcohol and a medication overdose, six had drugs and medication and two had all three. Overall, $35 \%$ of all the patients had an intoxication as alcohol, drugs or an overdose of medication at time of admission.

\section{Trauma characteristics}

All patients were taken to the hospital by ambulance. In $57 \%$ the injury was self-inflicted. $25 \%$ jumped from a height. Blunt trauma was more frequent than penetrating ( $72 \%$ vs $24 \%$ ). $57 \%$ needed a surgical intervention at least once, of those $43 \%$ needed more than one. $66 \%$ of the self-inflicted group needed surgery, while this was $51 \%$ in the unintentional group. Forty-three patients needed a chest drain and nine even needed chest drains at both sides. Seven patients underwent a radiological intervention (Table 2).
$18 \%$ had a GCS $\leq 8$ (Table 3 ). The ISS ranged from 1 to 59 (median, 13). 33\% had major traumas with an ISS $\geq 16$. $17 \%$ had a RTS $\geq 10.69 \%$ had an AIS $\geq 3$ to one or more body regions. Most common injuries of this group were of the head and neck (Fig. 1).

49\% had complications. Most common was a delirium (29\%), but also infections (24\%) such as pneumonia or urine tract infection were frequently seen. Complications related to the injury or psychiatric disorder led in 15 patients to a re-intervention, such as operation.

\section{Destinations of discharge}

Most patients were discharged to their home (34\%), of which $18 \%$ received ambulant psychiatric care (Fig. 2). Patients who were referred to a nursing home for rehabilitation also were included in the category nursing home. Twelve patients discharged themselves against medical advice and were declared mentally competent at that time.

Three patients came back to the emergency room of the VUmc within 30 days after discharge and were readmitted again. Five patients died within 30 days after admission in the hospital, four in the unintentional group and one in the self-inflicted group.

\section{Discussion}

The current study shows the data of the MPU of its first 10 years of existence. It shows the injury characteristics of self-inflicted and unintentional trauma in patients with psychiatric comorbidity in a level I trauma center. A series of 258 patients was enrolled, of which more than one-third had a history of previous admission to a psychiatric ward. The median age of trauma patients at the MPU (Table 1) was nearly similar to that of all patients admitted to the MPU(7); however, the male to female ratio was higher in the trauma patients only (1.8 versus 1.1$)$. The higher incidence of males may be explained by the fact that men more often choose high-risk methods with significantly higher lethality than women [12].

At least $25 \%$ of the patients in a general hospital have psychiatric comorbidity [13-15]. Several studies show that dementia, anxiety disorders, substance-related disorders and mood disorders are the most common [6, 15-17]. Most of the time it is not necessary to treat these patients at a special ward and their needs of psychiatric treatment are sufficiently met by the psychiatric consultation and liaison service. In case of severe behavioural disturbances, persisting suicidality, difficult diagnostics or serious non-compliance due to their psychiatric illness, admission to a MPU can prevail above staying on a normal care ward. The experienced staff of the MPU is trained in observation of psychiatric 
Table 2 Trauma characteristics of trauma patients admitted at MPU

\begin{tabular}{|c|c|c|c|c|c|c|}
\hline & $2006-2007$ & 2008-2009 & 2010-2011 & 2012-2013 & 2014-2015 & Total \\
\hline \multicolumn{7}{|l|}{ Type of transport, $N(\%)$} \\
\hline Ambulance & 39 (88.6) & $39(86.7)$ & $39(86.7)$ & $36(72.0)$ & $28(42.4)$ & $181(72.6)$ \\
\hline Ambulance (with MMT) & $1(2.3)$ & $3(6.7)$ & $4(8.9)$ & $9(18.0)$ & $31(47.0)$ & $48(19.2)$ \\
\hline On their own & $4(9.1)$ & $2(4.4)$ & $2(4.4)$ & $5(10.0)$ & $6(9.1)$ & $19(7.6)$ \\
\hline Police & 0 & $1(2.2)$ & 0 & 0 & $1(1.5)$ & $2(0.8)$ \\
\hline \multicolumn{7}{|l|}{ Trauma intent, $N(\%)$} \\
\hline Unintentional & $28(59.6)$ & $19(42.2)$ & $23(48.9)$ & $18(34.0)$ & $21(31.8)$ & $109(42.2)$ \\
\hline Self-inflicted & $19(40.4)$ & $26(57.8)$ & $24(51.1)$ & $35(66.0)$ & $43(65.2)$ & $147(57.0)$ \\
\hline \multicolumn{7}{|l|}{ Trauma mechanism, $N(\%)$} \\
\hline Fall & $19(40.4)$ & $10(22.2)$ & $18(38.3)$ & $10(18.9)$ & $13(19.7)$ & $70(27.1)$ \\
\hline Jump & $7(14.9)$ & $16(35.6)$ & $9(19.1)$ & $15(28.3)$ & $17(25.8)$ & $64(24.8)$ \\
\hline Stabbing & $10(21.3)$ & $6(13.3)$ & $11(23.4)$ & $11(20.8)$ & $14(21.2)$ & $52(20.2)$ \\
\hline Struck by/against traffic & $5(10.6)$ & $8(17.8)$ & $8(17.0)$ & $8(15.1)$ & $12(18.2)$ & $41(15.9)$ \\
\hline Flash burn & 0 & $2(4.4)$ & 0 & $3(5.7)$ & $1(1.5)$ & $6(2.3)$ \\
\hline Near drowning/submersion & $2(4.3)$ & 0 & 0 & 0 & $2(3.0)$ & $4(1.6)$ \\
\hline Gunshot & $1(2.1)$ & 0 & 0 & $1(1.9)$ & $2(3.0)$ & $4(1.6)$ \\
\hline Hanging/strangulation & 0 & $1(2.2)$ & 0 & $1(1.9)$ & 0 & $2(0.8)$ \\
\hline Other & $3(6.4)$ & $2(4.4)$ & $1(2.1)$ & $4(7.5)$ & $5(7.6)$ & $15(5.8)$ \\
\hline \multicolumn{7}{|l|}{ Mechanism of injury, $N(\%)$} \\
\hline Blunt & $33(70.2)$ & $36(80.0)$ & $35(74.5)$ & $36(67.9)$ & $45(68.2)$ & $185(71.7)$ \\
\hline Penetrating & $12(25.5)$ & $7(15.6)$ & $12(25.5)$ & $14(26.4)$ & $18(27.3)$ & $63(24.4)$ \\
\hline Flash burn & 0 & $2(4.4)$ & 0 & $3(5.7)$ & $1(1.5)$ & $6(2.3)$ \\
\hline Drowning/submersion & $2(4.3)$ & 0 & 0 & 0 & $2(3.0)$ & $4(1.6)$ \\
\hline \multicolumn{7}{|l|}{ No. of surgical interventions, $N(\%)$} \\
\hline 1 & $20(42.6)$ & $13(28.9)$ & $13(27.7)$ & $13(24.5)$ & $25(37.9)$ & $84(32.6)$ \\
\hline 2 & $4(8.5)$ & $4(8.9)$ & $7(14.9)$ & $9(17.0)$ & $8(12.1)$ & $25(9.7)$ \\
\hline 3 & 0 & $4(8.9)$ & $2(4.3)$ & $4(7.5)$ & $7(10.6)$ & $17(6.6)$ \\
\hline 4 & $1(2.1)$ & $3(6.7)$ & $3(6.4)$ & $4(7.5)$ & $2(3.0)$ & $13(5.0)$ \\
\hline$>4$ & $1(2.1)$ & $1(2.2)$ & $2(4.3)$ & $3(5.6)$ & $1(1.5)$ & $8(3.1)$ \\
\hline Complications, $N(\%)$ & $29(63.0)$ & $22(48.9)$ & $25(53.2)$ & $21(39.6)$ & $29(43.9)$ & $126(49.0)$ \\
\hline \multicolumn{7}{|l|}{ Related to injury/psychiatric disorder } \\
\hline Wound problems & $3(6.4)$ & $5(11.1)$ & $6(12.8)$ & $7(13.2)$ & $9(13.6)$ & $30(11.6)$ \\
\hline Haemorrhage & 0 & 0 & $2(4.3)$ & 0 & 0 & $2(0.8)$ \\
\hline Suicide attempt/self-mutilation during admission & $1(2.1)$ & 0 & $2(4.3)$ & $1(1.9)$ & 0 & $4(1.6)$ \\
\hline Other & $1(2.1)$ & $3(6.7)$ & $3(6.4)$ & $3(5.7)$ & $8(12.1)$ & $18(7.0)$ \\
\hline \multicolumn{7}{|l|}{ General } \\
\hline Infections & $14(29.8)$ & $9(20.0)$ & $11(23.4)$ & $13(24.5)$ & $14(21.2)$ & $61(23.6)$ \\
\hline Delirium & $19(40.4)$ & $16(35.6)$ & $17(36.2)$ & $9(17.0)$ & $14(21.2)$ & $75(29.1)$ \\
\hline Other & $11(23.4)$ & $3(6.7)$ & $2(4.3)$ & $1(1.9)$ & $1(1.5)$ & $18(7.0)$ \\
\hline Missed injury & $2(4.3)$ & $4(8.9)$ & $4(8.5)$ & $2(3.8)$ & $2(3.0)$ & $14(5.4)$ \\
\hline No. of re-interventions because of complications & $3(6.4)$ & $3(6.7)$ & $2(4.3)$ & $2(3.77)$ & $5(7.6)$ & $15(5.8)$ \\
\hline Total & $47(18.2)$ & $45(17.4)$ & $47(18.2)$ & $53(20.5)$ & $66(25.6)$ & $258(100)$ \\
\hline
\end{tabular}

symptoms, skilled in the approach and treatment of patients with different psychiatric problems and has the knowledge and creativity to turn non-compliance into compliance. In this study, there was a large variation seen in psychiatric disorders at the MPU. Most common were substancerelated disorders, what is not remarkable. Substance abuse is highly associated with unintentional and intentional traumatic injuries [18-20]. It even is reported that a quarter of the posttraumatic acute care patients have alcohol abuse or dependency [19]. Second-most common were psychotic disorders; these patients are known at high risk for attempted and completed suicide [21]. A severe postoperative delirium 
Table 3 Trauma scores of patients admitted at MPU and all trauma patients at the ER of VUmc

\begin{tabular}{lll}
\hline & MPU VUmc (\%) & $\begin{array}{l}\text { General at } \\
\text { ER VUmc } \\
(\%)\end{array}$ \\
\hline $\mathrm{ISS} \geq 16$ & 32.6 & 15.3 \\
$\mathrm{GCS} \leq 8$ & 18.4 & 5.5 \\
$\mathrm{RTS} \leq 10$ & 16.7 & 3.3 \\
\hline
\end{tabular}

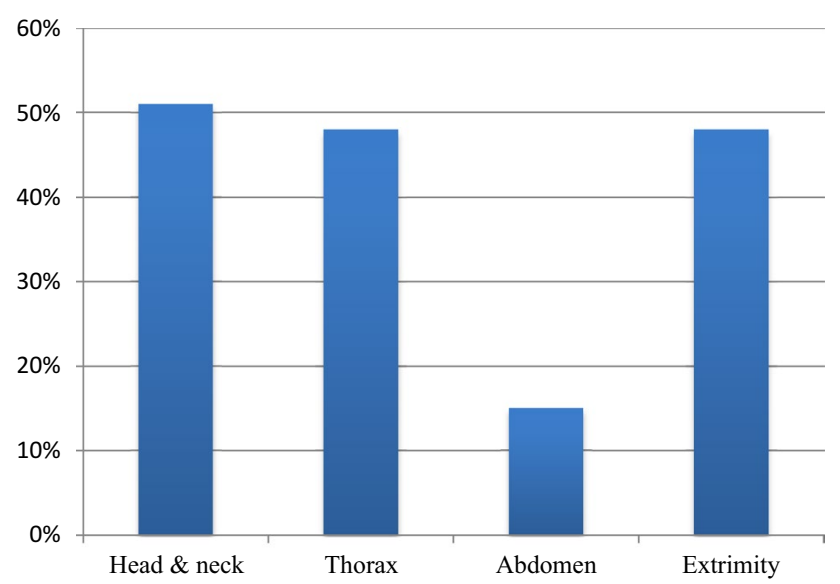

Fig. 1 Patterns of injury with an AIS $>3$ of trauma patients with ISS $>16$ admitted at MPU $(n=61)$

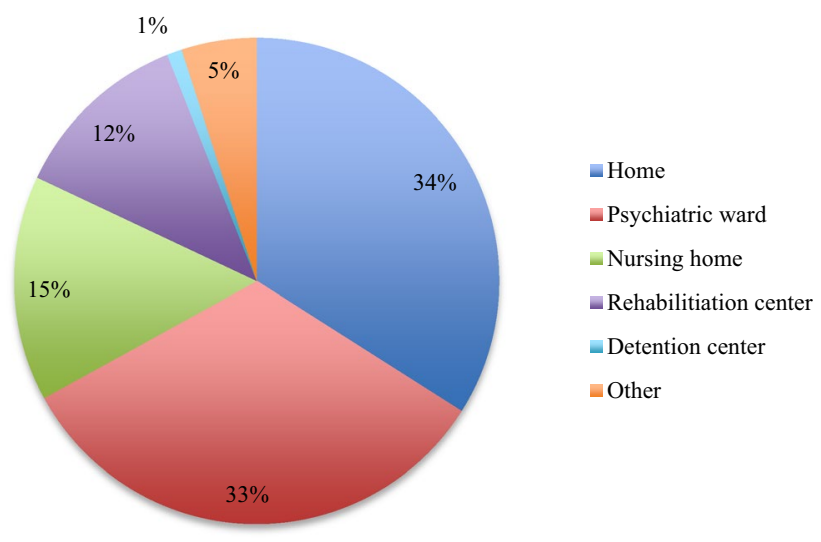

Fig. 2 Destination of discharge of trauma patients admitted at MPU

or post-concussion syndrome can also be a very important diagnosis for transfer to this specific ward [22].

Stabbing is a serious form of self-inflicted trauma with sometimes very severe injuries but most of the time nonlethal [23]. Blunt trauma mechanism was the most frequently seen type of injury and almost a quarter of all injuries were penetrating, which is high compared with all trauma patients admitted to the VUmc between 2006 and 2016 (4.7\%).
An Injury Severity Score of 16 or higher was found in at least $33 \%$, this is twice the number compared to all trauma patients who were admitted at VUmc between 2006 and 2016 (Table 3). Also the GCS and RTS were more severe in our patient population compared to all trauma patients admitted at VUmc. Since severely injured patients need to be transferred to a level I trauma center, level I trauma centers probably benefits from these MPU units.

The complication rate of $49 \%$ is high when compared to trauma patients without a mental disorder, which is $36 \%$ in according to Fang et al. [24]. However, compared with multitrauma patients this percentage reflects the literature. Saltzherr et al. even describes complication rates up to $60 \%$ in multitrauma patients [25]. A systematic review of Walburn et al. describes psychological stress is associated with impaired wound problems by modulating the immune function [25], which may contribute the high rate of complications in this group.

Although the fact that the reattempted suicide rate in trauma patients in this study is low, some studies reported a high risk of reattempts after parasuicide [26] and some reported low. Pajonk et al. describes a relatively low reattempted suicide rate after severe suicide attempts [27]. All five patients who died within 30 days after admission were above the age of 75 and died of complications.

\section{Limitations}

The retrospective design is the main limitation of this study. With the number of patients we received from the Research Data Platform, we may have missed a few patients whose date of admission did not correlate with the date the diagnosis was given. The MPU is a type IV ward that receives patients that do not need high or intensive care. For this reason, psychiatric patients with major trauma who died at the intensive care and never made it to the MPU were not included in this study. Also because of the retrospective nature this study is subjective to information bias (by incomplete data).

Re-admission because of relapse could only be traced when patients returned to the emergency room at the VUmc. It is not known if patients were readmitted to other hospitals. The number of three patients is, therefore, highly likely underrated. Furthermore, all these three patients were not readmitted for the trauma surgery.

\section{Conclusions}

Since all previous reports about MPU's focused on the complete population hospitalised at a MPU, no literature is available about trauma patients specifically. This study shows that $33 \%$ were major trauma patients and $35 \%$ used alcohol, 
drugs or a medication overdose at the time of admission. Penetrating trauma was five times more common compared to the overall population of trauma patients admitted to VUmc. Therapy was frequently interfered by the psychiatric disorder and may have resulted in the high complication rate (when compared to the literature). A unit with special trained staff to take care of these complex patients and close co-operation between surgery and psychiatry is important. In particular, level I trauma centers may benefit from a MPU. There were no trends or large differences observed in the last 10 years. Considered together, prospective research is needed to investigate possible benefit and/or effectiveness of admission at the MPU and care compared to normal care on regular wards.

\section{Compliance with ethical standards}

Conflict of interest Lisette Dekker, Hansje Heller, Jessica van der Meij, Annelies Toor and Leo Geeraedts declare that they have no conflict of interest.

\section{References}

1. CBS. Aantal zelfdodingen weer fors gestegen. 2014. https://www. cbs.nl/nl-nl/nieuws/2014/50/aantal-zelfdodingen-weer-fors-geste gen. Accessed Dec 2014

2. CBS. Ziekenhuisopnamen; geslacht, leeftijd en diagnoseindeling VTV. http://statline.cbs.nl/Statweb/publicatio $\mathrm{n} / ? \mathrm{DM}=\mathrm{SLNL} \& \mathrm{PA}=71859 \mathrm{ned} \& \mathrm{D} 1=1,3,5,7-8 \& \mathrm{D} 2=1$ $2 \& \mathrm{D} 3=0 \& \mathrm{D} 4=189 \& \mathrm{D} 5=0,9,14,19,24-31 \& \mathrm{VW}=\mathrm{T}$. Accessed June 2014

3. Clous EA, Ponsen KJ, van Hensbroek PB, Luitse JS, Olff M, Goslings JC. Falling from a height: Psychiatric comorbidity and complications. Ned Tijdschr Geneeskd. 2015;159:A7729.

4. Topp T, Muller T, Kiriazidis I, Lefering R, Ruchholtz S, Trauma Registry of the German Trauma S, et al. Multiple blunt trauma after suicidal attempt: an analysis of 4754 multiple severely injured patients. Eur J Trauma Emerg Surg. 2012;38(1):19-24.

5. Zatzick DF, Kang SM, Kim SY, Leigh P, Kravitz R, Drake C, et al. Patients with recognized psychiatric disorders in trauma surgery: incidence, inpatient length of stay, and cost. J Trauma. 2000;49(3):487-95.

6. Alberque C, Gex-Fabry M, Whitaker-Clinch B, Eytan A. The 5 -year evolution of a mixed psychiatric and somatic care unit: a European experience. Psychosomatics. 2009;50(4):354-61.

7. Honig A, Visser I, Heller H, Kieviet N, Boenink AD. A medical-psychiatric unit in a general hospital: effective combined somatic and psychiatric care?. Ned Tijdschr Geneeskd. 2014;158(5):A6520.

8. Findley JK, Sanders KB, Groves JE. The role of psychiatry in the management of acute trauma surgery patients. Prim Care Companion J Clin Psychiatry. 2003;5(5):195-200.

9. Poole GV, Lewis JL, Devidas M, Hauser CJ, Martin RW, Thomae KR. Psychopathologic risk factors for intentional and nonintentional injury. J Trauma. 1997;42(4):711-5.
10. Kathol RG, Harsch HH, Hall RC, Shakespeare A, Cowart T. Categorization of types of medical/psychiatry units based on level of acuity. Psychosomatics. 1992;33(4):376-86.

11. Baker SP, O'Neill B, Haddon W Jr, Long WB. The injury severity score: a method for describing patients with multiple injuries and evaluating emergency care. J Trauma. 1974;14(3):187-96.

12. Mergl R, Koburger N, Heinrichs K, Szekely A, Toth MD, Coyne $\mathrm{J}$, et al. What are reasons for the large gender differences in the lethality of suicidal acts? An epidemiological analysis in four European Countries. PLoS One. 2015;10(7):e0129062.

13. Martucci M, Balestrieri M, Bisoffi G, Bonizzato P, Covre MG, Cunico L, et al. Evaluating psychiatric morbidity in a general hospital: a two-phase epidemiological survey. Psychol Med. 1999;29(4):823-32.

14. van Waarde JA, Richter C, Muller ME, Verwey B. The medicalpsychiatric unit: added value for patients, physicians and hospitals. Ned Tijdschr Geneeskd. 2004;148(5):209-11.

15. Wancata J, Benda N, Windhaber J, Nowotny M. Does psychiatric comorbidity increase the length of stay in general hospitals? Gen Hosp Psychiatry. 2001;23(1):8-14.

16. Katz K, Gonen N, Goldberg I, Mizrahi J, Radwan M, Yosipovitch $\mathrm{Z}$. Injuries in attempted suicide by jumping from a height. Injury. 1988;19(6):371-4.

17. Leue C, Driessen G, Strik JJ, Drukker M, Stockbrugger RW, Kuijpers PM, et al. Managing complex patients on a medical psychiatric unit: an observational study of university hospital costs associated with medical service use, length of stay, and psychiatric intervention. J Psychosom Res. 2010;68(3):295-302.

18. Blondell RD, Dodds HN, Looney SW, Lewis CM, Hagan JL, Lukan JK, et al. Toxicology screening results: injury associations among hospitalized trauma patients. J Trauma. 2005;58(3):561-70.

19. Zatzick D, Jurkovich G, Russo J, Roy-Byrne P, Katon W, Wagner A, et al. Posttraumatic distress, alcohol disorders, and recurrent trauma across level 1 trauma centers. J Trauma. 2004;57(2):360-6.

20. Worrell SS, Koepsell TD, Sabath DR, Gentilello LM, Mock $\mathrm{CN}$, Nathens $\mathrm{AB}$. The risk of reinjury in relation to time since first injury: a retrospective population-based study. J Trauma. 2006;60(2):379-84

21. De Hert M, McKenzie K, Peuskens J. Risk factors for suicide in young people suffering from schizophrenia: a long-term follow-up study. Schizophr Res. 2001;47(2-3):127-34.

22. Lederbogen F, Kopf D, Hewer W. An interdisciplinary unit for major psychiatric/somatic comorbidity: concept and 22 years of experience. Nervenarzt. 2008;79(9):1051-8.

23. Abdullah F, Nuernberg A, Rabinovici R. Self-inflicted abdominal stab wounds. Injury. 2003;34(1):35-9.

24. Fang JF, Shih LY, Lin BC, Hsu YP. Pelvic fractures due to falls from a height in people with mental disorders. Injury. 2008;39(8):881-8.

25. Saltzherr TP, Visser A, Ponsen KJ, Luitse JS, Goslings JC. Complications in multitrauma patients in a Dutch level 1 trauma center. J Trauma. 2010;69(5):1143-6.

26. Sawa M, Koishikawa H, Osaki Y. Risk factors of a suicide reattempt by seasonality and the method of a previous suicide attempt: a cohort study in a Japanese Primary Care Hospital. Suicide Life Threat Behav. 2016;47:688-695.

27. Pajonk FG, Ruchholtz S, Waydhas C, Schneider-Axmann T. Longterm follow-up after severe suicide attempt by multiple blunt trauma. Eur Psychiatry. 2005;20(2):115-20. 